\title{
Tamanho de Órgãos e Vísceras de Bezerros Holandeses, para Produção de Vitelos, Recebendo Dietas com Diferentes Níveis de Concentrado ${ }^{1}$
}

\section{Telma Regina Ribeiro², José Carlos Pereira ${ }^{3}$, Maria Ignez Leão ${ }^{3}$, Marcus Vinícius Morais de Oliveira 4 , Augusto César de Queiroz ${ }^{3}$, Paulo Roberto Cecon ${ }^{5}$, Rosana Coelho de Alvarenga e Melo4}

\begin{abstract}
RESUMO - O experimento foi realizado com 20 bezerros holandeses puros por cruza, todos machos não castrados, com 75 dias de idade e peso médio de $76 \mathrm{~kg}$, submetidos ao mesmo sistema de aleitamento antes do experimento. O objetivo foi avaliar o tamanho relativo dos órgãos internos e vísceras dos animais alimentados com dietas contendo 45, 60, 75 e $90 \%$ de concentrado. As dietas foram constituídas de feno de coastcross, fubá de milho, farelo de soja e mistura mineral, fornecidas à vontade. O delineamento experimental foi em blocos casualizados, com quatro tratamentos e cinco repetições. O período experimental foi variável para cada tratamento, em que os animais foram abatidos à medida que atingiram o peso vivo médio de $200 \mathrm{~kg}$ e, antes do abate, foram submetidos a jejum de 16 horas. À medida que se aumentaram os níveis de concentrado nas dietas, os pesos absolutos do fígado, rins, pulmões, abomaso, mesentério e a gordura presentes nas carcaças aumentaram linearmente. Não houve diferença significativa para o peso dos demais órgãos e vísceras, assim como para as partes não constituintes das carcaças como couro, patas, cabeça e cauda, em relação aos níveis de concentrado estudados.
\end{abstract}

Palavras-chave: bezerros holandeses, níveis de concentrado, órgãos internos, vísceras, vitelos

\section{Size of Internal Organs and Viscera of Holstein Veal Calves Fed Diets Containing Various Levels of Concentrate}

\begin{abstract}
The experiment was carried out with 20 intact Holstein male calves, 75 days old, with mean live weight of $76 \mathrm{~kg}$, submitted to the same nursing system before starting the experiment. The objective was to evaluate the relative size of internal organs and viscera of these animals fed diets containing 45, 60, 75 and 90\% of concentrate. Diets were composed of coastcross hay, ground corn grain, soybean meal and mineral mixture. The experimental design was a randomized blocks, with four treatments and five replicates. The experimental period was different for each treatment, where the animals were slaughtered as they reached a mean weight of $200 \mathrm{~kg}$. Before slaughter, the animals were fasted for 16 hours. The absolute weights for the liver, kidneys, lungs, abomasum, mesentery and fat present in the carcass linearly increased as the levels of concentrate in the diets increased. There were no significant differences for the weight of the other organs and viscera, nor for the non constituint parts of the carcasses of the animals, as leather, feet, head and tail, in relation to the levels of the concentrate.
\end{abstract}

Key Words: Holstein calves, internal organs, level of concentrate, veal calves, viscera

\section{Introdução}

Os baixos índices reprodutivos da pecuária de corte têm conduzido técnicos e produtores à procura de práticas alternativas que permitam acréscimos na produção de bezerros (ALBOSPINO e LOBATO, 1994). Para isso, devem ser criadas condições para realização de investimentos, a fim de melhorar a produtividade do rebanho, além de verificar a possibilidade de aproveitamento dos bezerros para abate, provenientes de raças produtoras de leite (DODE et al., 1986). Neste ponto, as pesquisas sobre as carac- terísticas das carcaças de bezerros no Brasil, principalmente de bezerros holandeses criados em regime de confinamento, ainda são escassas.

O estudo das partes não-integrantes da carcaça é importante, pois essas têm influência direta sobre o rendimento desta (BERG e BUTTERFIELD,1979 e OLIVEIRA et al., 1994); além disso, o conteúdo do trato gastrintestinal pode explicar o aumento de $30 \%$ do peso vivo, dependendo do regime nutricional (PRESTON e WILLIS, 1974).

MULLER (1980) enfatiza que o estudo de carcaças tem como finalidade avaliar aqueles

\footnotetext{
${ }^{1}$ Parte da tese apresentada à UFV, pelo segundo autor, para obtenção do título de Mestre em Zootecnia, financiada pelo CNPq.

2 Eng ${ }^{\circ}-\mathrm{Agr}^{\circ}, \mathrm{MS}$ em Zootecnia.

3 Professores do DZO/Universidade Federal de Viçosa, Bolsistas do CNPq.

${ }^{4}$ Zootecnista, Estudantes de Doutorado do DZO/UFV e DEA/UFV. E.mail: ds16672@correio.ufv.br; zana@dea.ufv.br

${ }^{5}$ Professor do DPI/UFV.
} 
parâmetros que podem ser, subjetiva ou objetivamente, medidos e são correlacionados com os aspectos quantitativos e qualitativos da mesma. A qualidade da carne, assim como o rendimento da carcaça, também depende de vários fatores relativos ao meio ambiente e ao próprio animal, como o peso do aparelho digestivo, da gordura visceral, do sangue, cabeça, cauda e patas.

Poucos estudos são realizados em relação aos componentes externos e aos orgãos corporais. Possivelmente deve-se ao fato destas variáveis não fazerem parte da carcaça comercial. No entanto, dados sobre estes componentes são importantes, já que os orgãos internos, por meio de processamento adequado, podem tornar-se subprodutos valiosos da indústria de carne, além de contribuir para estudos biológicos, nutricionais e medicinais (KIRTON et al., 1995).

Objetivou-se neste trabalho verificar o tamanho relativo dos órgãos internos e vísceras de bezerros holandeses submetidos a dietas contendo diferentes níveis de concentrado.

\section{Material e Métodos}

Foram utilizados 20 bezerros holandeses puros por cruza (HPC), machos não-castrados, com idade aproximada de 75 dias e peso médio de $76 \mathrm{~kg}$, mantidos em regime de confinamento, em baias individuais cobertas de $8 \mathrm{~m}^{2}$, com piso concretado, providas de comedouro e bebedouro.

Do nascimento até o início do experimento, os animais foram submetidos a um único sistema de aleitamento, que consistiu de quatro litros de uma mistura preparada com sucedâneo comercial do leite, fornecidos duas vezes ao dia, durante 60 dias. Todos os animais durante esse período tiveram acesso a volumoso - feno de capim coastcross (Cynodon dactylon (L.) Pers.) picado - e ração concentrada à vontade.

Os 20 animais foram sorteados aleatoriamente, em cinco blocos com quatro animais cada, distribuídos ao acaso entre quatro tratamentos, que compreenderam quatro níveis de concentrado na dieta: 45 , 60,75 e $90 \%$ na matéria seca.

$\mathrm{O}$ período de adaptação às instalações e ao sistema de manejo empregado teve duração de 15 dias, durante o qual todos os animais receberam a ração utilizada no período experimental à vontade; além de receberem vitamina A injetável, foram tratados contra endo e ectoparasitas, pesados e identificados.

O período experimental foi variável para cada tratamento, sendo que os animais eram abatidos à medida que atingiam o peso médio de $200 \mathrm{~kg}$, estabelecido em função do sistema de produção proposto para o trabalho.

As dietas foram fornecidas, à vontade, uma vez ao dia, pela manhã, e calculadas com base nas exigências nutricionais estabelecidas pelo NRC (1988), para um ganho de peso esperado de $1,0 \mathrm{~kg}$ diário. A constituição das dietas, os ingredientes e respectivas composições são apresentadas nas Tabelas 1,2 e 3.

Foram feitas pesagens a cada 28 dias e, à medida que os animais de cada baia atingiam o peso vivo médio de $200 \mathrm{~kg}$, eram abatidos, sendo submetidos a um período de jejum alimentar prévio de cerca de 16 horas, mas com livre acesso à água. Imediatamente antes do abate, cada animal era pesado, obtendo-se seu peso vivo final (PVF). Após o abate, o trato gastrintestinal cheio foi removido e pesado, a seguir, esvaziado e lavado; sendo novamente pesado, obtendo-se assim o seu peso vazio. Deduzindo-se o peso do trato gastrintestinal cheio do seu peso vazio, obtinha-se o peso do conteúdo do trato gastrintestinal, que, subtraindo-se do peso vivo final, obtinha-se o peso de corpo vazio (PCVZ) de cada animal. A seguir,

Tabela 1 - Composição percentual dos ingredientes das rações (base da matéria seca)

Table 1 - Percentage composition of ingredients of the diets (dry matter basis)

\begin{tabular}{|c|c|c|c|c|}
\hline \multirow[t]{2}{*}{$\begin{array}{l}\text { Ingredientes } \\
\text { Ingredients }\end{array}$} & \multicolumn{4}{|c|}{$\begin{array}{c}\text { Rações } \\
\text { Diets }\end{array}$} \\
\hline & 45 & 60 & 75 & 90 \\
\hline $\begin{array}{l}\text { Feno coastcross } \\
\text { Coastcross hay }\end{array}$ & 54,10 & 38,80 & 23,49 & 8,20 \\
\hline $\begin{array}{l}\text { Fubá de milho } \\
\text { Ground corn grain }\end{array}$ & 24,44 & 41,20 & 57,97 & 74,49 \\
\hline $\begin{array}{l}\text { Farelo de soja } \\
\text { Soybean meal }\end{array}$ & 20,56 & 18,80 & 17,04 & 15,51 \\
\hline $\begin{array}{l}\text { Mistura mineral }^{1} \\
\text { Mineral mixture }^{1}\end{array}$ & 0,45 & 0,60 & 0,75 & 0,90 \\
\hline $\begin{array}{l}\text { Calcário } \\
\text { Limestone }\end{array}$ & 0,45 & 0,60 & 0,75 & 0,90 \\
\hline
\end{tabular}

1 Mistura mineral contendo em cada $\mathrm{kg}: 420 \mathrm{~g}$ de fosfato bicálcico, $54 \mathrm{~g}$ de calcário calcítico; $519,12 \mathrm{~g}$ de cloreto de sódio; $2,0 \mathrm{~g}$ de sulfato de cobre; $4 \mathrm{~g}$ de óxido de zinco; $0,3 \mathrm{~g}$ de iodato de cálcio; $0,5 \mathrm{~g}$ de sulfato de cobalto e $0,8 \mathrm{~g}$ selenito de sódio.

1 Mineral mix contents per $\mathrm{kg}: 420 \mathrm{~g}$ of dicalcium phosphate; $54 \mathrm{~g}$ of limestone; $519.12 \mathrm{~g}$ of sodium chloride; $2.0 \mathrm{~g}$ of cooper sulphate; $4.0 \mathrm{~g}$ of zinc oxide; $0.3 \mathrm{~g}$ of calcium iodate; $0.5 \mathrm{~g}$ of cobalt sulphate and $0.8 \mathrm{~g}$ of sodium selenite. 
pesaram-se, individualmente, cabeça, patas, couro, rúmen-retículo, omaso, abomaso, intestino delgado, intestino grosso, gordura interna, fígado, coração, rins, baço, pulmões, língua, sangue, mesentério, carne industrial, cauda, além de esôfago, traquéia e aparelho reprodutor (APARAS), que foram pesados em conjunto.

O trabalho foi conduzido em delineamento em blocos casualizados, com quatro tratamentos e cinco repetições, sendo os dados interpretados por meio de análises de variância e regressão. Os modelos foram escolhidos com base na significância dos coeficientes de regressão, pelo teste " $t$ " de Student a 5\%, pelo coeficiente de determinação, utilizando-se o programa SAEG (Sistema de Análises Estatísticas e Genéticas), conforme UNIVERSIDADE FEDERAL DE VIÇOSA - UFV (1995).

O modelo matemático utilizado foi:

$$
\mathrm{Y}_{\mathrm{ij}}=\mu+\mathrm{b}_{\mathrm{j}}+\mathrm{t}_{\mathrm{i}}+\mathrm{e}_{\mathrm{ij}}
$$

em que $Y_{i j}=$ variável observada em questão, no tratamento $\mathrm{i}$, no bloco $\mathrm{j} ; \mu=$ média geral; $\mathrm{b}_{\mathrm{j}}=$ efeito do

Tabela 2 - Teores de matéria seca (MS), proteína bruta (PB) e fibra em detergente neutro (FDN) das rações experimentais

Table 2 - Drymatter (DM), crude protein $(C P)$ and neutral detergent fiber (NDF) contents of the experimental diets

\begin{tabular}{lcccc}
\hline & \multicolumn{4}{c}{$\begin{array}{c}\text { Rações } \\
\text { Diets }\end{array}$} \\
\cline { 2 - 5 } & 45 & 60 & 75 & 90 \\
\hline MS $(D M)$ & 86,99 & 86,60 & 86,21 & 85,83 \\
PB $(C P)$ & 16,39 & 15,99 & 15,57 & 15,26 \\
FDN $(N D F)$ & 51,04 & 40,05 & 29,05 & 18,08 \\
\hline
\end{tabular}

Tabela 3 - Teores de matéria seca (MS), proteína bruta (PB) e fibra em detergente neutro (FDN) dos ingredientes das rações experimentais

Table 3 - Drymatter(DM), crude protein (CP) and neutral detergent fiber (NDF) contents of the ingredients of the experimental diets

\begin{tabular}{lccc}
\hline $\begin{array}{l}\text { Ingredientes } \\
\text { Ingredients }\end{array}$ & $\begin{array}{c}\text { MS (\%) } \\
D M(\%)\end{array}$ & $\begin{array}{c}\text { PB (\%MS) } \\
C P(\% D M)\end{array}$ & $\begin{array}{c}\text { FDN }(\% \mathrm{MS}) \\
\text { NDF }(\% D M)\end{array}$ \\
\hline $\begin{array}{l}\text { Feno de coastcross } \\
\begin{array}{l}\text { Coastcross hay } \\
\text { Fubá de milho }\end{array}\end{array}$ & 88,22 & 6,77 & 83,40 \\
$\begin{array}{l}\text { Maize flour } \\
\text { Farelo de soja } \\
\text { Soybean meal }\end{array}$ & 87,38 & 9,10 & 12,10 \\
\hline
\end{tabular}

bloco $\mathrm{j}$, sendo $\mathrm{j}=1,2, . ., 5 ; \mathrm{t}_{\mathrm{i}}=$ efeito do tratamento $\mathrm{i}$, sendo $\mathrm{i}=$ níveis de concentrado nas dietas $(45,60,75$, 90); e = erro aleatório.

\section{Resultados e Discussão}

O peso vivo médio estimado após jejum, por ocasião do abate, foi de $194,18 \mathrm{~kg}$ e o peso do corpo vazio, de $165,17 \mathrm{~kg}$. As análises de variância para peso de alguns órgãos e vísceras avaliados não mostraram efeito significativo $(\mathrm{P}>0,05)$ dos níveis de concentrado nas dietas. Os resultados para baço, língua, carne industrial, aparas, rúmen, retículo, intestino delgado, intestino grosso e gordura interna, conforme dados da Tabela 4, com seus valores absolutos, foram constantes para todos os níveis de concentrado nas dietas.

As análises de regressão mostraram efeito quadrático $(\mathrm{P}<0,01)$ para coração e efeito linear crescente $(\mathrm{P}<0,05)$ para rins, fígado e pulmões. As Figuras 1 e 2 mostram a representação gráfica das

Tabela 4 - Médias dos valores absolutos $(\mathrm{kg})$ para baço língua, carne industrial, aparas (esôfago + traquéia + aparelho reprodutor), rúmen, retículo, intestino delgado, intestino grosso e gordura interna

Table 4 - Average absolute values $(\mathrm{kg})$ of spleen, tongue, industrial meat, scraps(esofhagus + windpipe + reproductive organ), rumen, reticulum, small intestine, large intestine and internal fat

Orgãos e visceras Níveis de concentrado nas dietas

Organs and visceras Levels of concentrate in the diets

\begin{tabular}{|c|c|c|c|c|c|}
\hline & 45 & 60 & 75 & 90 & $\begin{array}{l}\text { Média } \\
\text { Mean }\end{array}$ \\
\hline Baço & 0,64 & 0,58 & 0,63 & 0,83 & 0,67 \\
\hline $\begin{array}{l}\text { Spleen } \\
\text { Língua }\end{array}$ & 0,58 & 0,63 & 0,63 & 0,62 & 0,62 \\
\hline $\begin{array}{l}\text { Tongue } \\
\text { Carne industrial }\end{array}$ & 1,05 & 1,11 & 1,05 & 0,98 & 1,05 \\
\hline $\begin{array}{l}\text { Industrial meat } \\
\text { Aparas } \\
\text { Scraps }\end{array}$ & 1,78 & 1,66 & 1,74 & 1,78 & 1,74 \\
\hline $\begin{array}{l}\text { Rúmen } \\
\text { Rumen }\end{array}$ & 3,05 & 3,47 & 3,03 & 3,44 & 3,25 \\
\hline $\begin{array}{l}\text { Retículo } \\
\text { Reticulum }\end{array}$ & 0,38 & 0,43 & 0,39 & 0,47 & 0,42 \\
\hline $\begin{array}{l}\text { Intestino delgado } \\
\text { Small intestine }\end{array}$ & 4,88 & 5,03 & 4,32 & 4,22 & 4,61 \\
\hline $\begin{array}{l}\text { Intestino grosso } \\
\text { Large intestine }\end{array}$ & 2,10 & 2,20 & 1,99 & 2,05 & 2,09 \\
\hline $\begin{array}{l}\text { Gordura interna } \\
\text { Internal fat }\end{array}$ & 2,10 & 2,90 & 2,88 & 2,51 & 2,60 \\
\hline
\end{tabular}


equações de regressão e seus respectivos coeficientes de determinação.

Os animais que foram alimentados com dietas contendo maiores níveis de concentrado, conseqüentemente, consumiram mais energia e, dessa maneira, apresentaram maior tamanho relativo dos órgãos vitais.

FERREL et al. (1976) concluíram que a maior massa de órgãos vitais, aliada à sua elevada atividade metabólica, resulta em maiores exigências de mantença, nos animais de raças leiteiras. Outros trabalhos também mostraram que as necessidades energéticas dos órgãos variam com o seu peso relativo, além de serem afetadas pelo nível nutricional, sendo maiores que as exigidas pelo tecido muscular (JONES et al., 1985; FERREL e JENKINS, 1985; FERRREL et al., 1986).

Mesmo quando os animais são submetidos à baixa restrição alimentar por longo período de tempo, o coração e os pulmões mantêm sua integridade, apresentando prioridade para a utilização dos nutrientes. Já rins e baço têm prioridade mais baixa que coração e pulmões na utilização dos nutrientes, quando os animais experimentaram crescimento mais pronunciado do tecido adiposo e muscular (PERON, 1991).

Para a variável omaso, a equação que melhor descreveu os resultados foi o modelo quadrático $(\mathrm{P}<0,10)$ e para abomaso, o linear $(\mathrm{P}<0,05)$. As

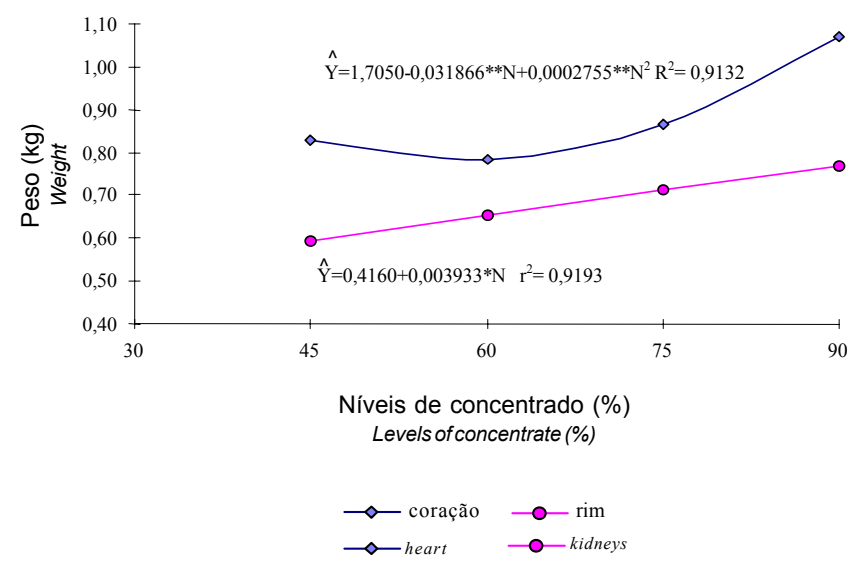

Figura 1 - Estimativa do peso absoluto de coração e rins dos animais, em função dos níveis de concentrado nas dietas.

Figure 1 - Estimate of absolute weight of heart and kidneys of the animals, in relation to the levels of concentrate in the diets.

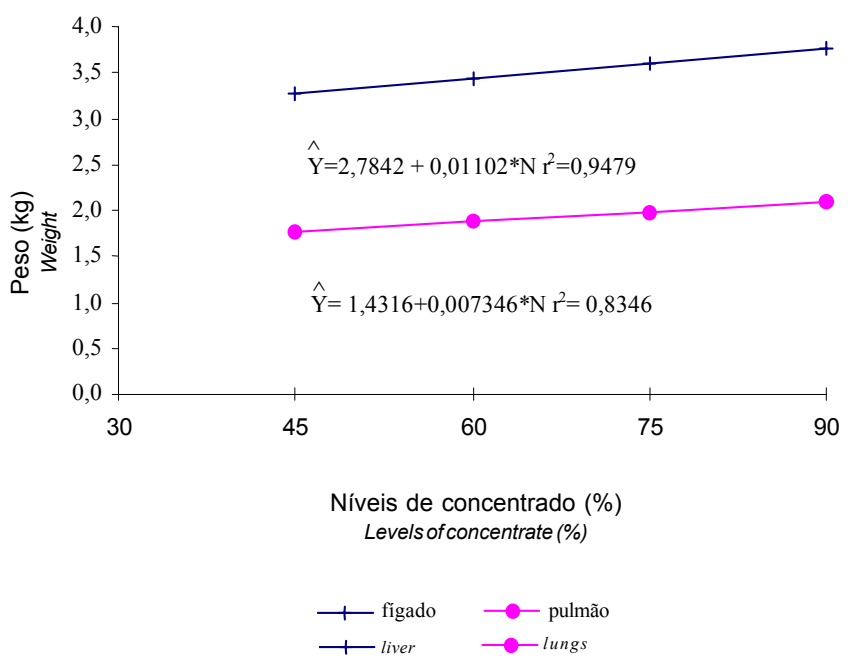

Figura 2 - Estimativa dos pesos absolutos de fígado e pulmões dos animais, em função dos níveis de concentrado nas dietas.

Figure 2 - Estimate of absolute weight of liver and lungs of the animals, in relation to the levels of concentrate in the diets.

equações e seus respectivos coeficientes de determinação podem ser observados na Figura 3.

O resultado encontrado para maior peso do omaso em animais alimentados com $45 \%$ de concentrado pode ser explicado pela alta ingestão de fibra e, possivelmente, pelo tamanho das partículas e do tempo de retenção pelo omaso.

Os resultados acima descritos estão de acordo com JONES et al. (1985), que encontraram, proporcionalmente, maiores tamanhos do omaso para animais alimentados com dietas à base de forragem ( $50 \%$ de silagem de milho $+50 \%$ de feno), quando comparados aos animais que receberam dietas à base de concentrado $(30 \%$ silagem de milho $+70 \%$ mistura de milho com base na matéria seca).

Segundo Bell et al. (1974), citados por LUCCI (1989), os animais alimentados com feno picado consumiram menos matéria seca e ganharam menos peso em relação aqueles alimentados apenas com concentrados ou concentrados mais feno moído. Esses fatos parecem lembrar a possibilidade de uma passagem mais rápida dos concentrados pelo rúmen e, conseqüentemente, a digestão ocorrendo principalmente no intestino delgado.

Quanto ao abomaso, seu volume e sua musculatura crescem em proporção aproximada aos ganhos de peso do corpo, de maneira independente da dieta

Rev. bras. zootec., 30(6S):2163-2168, 2001 


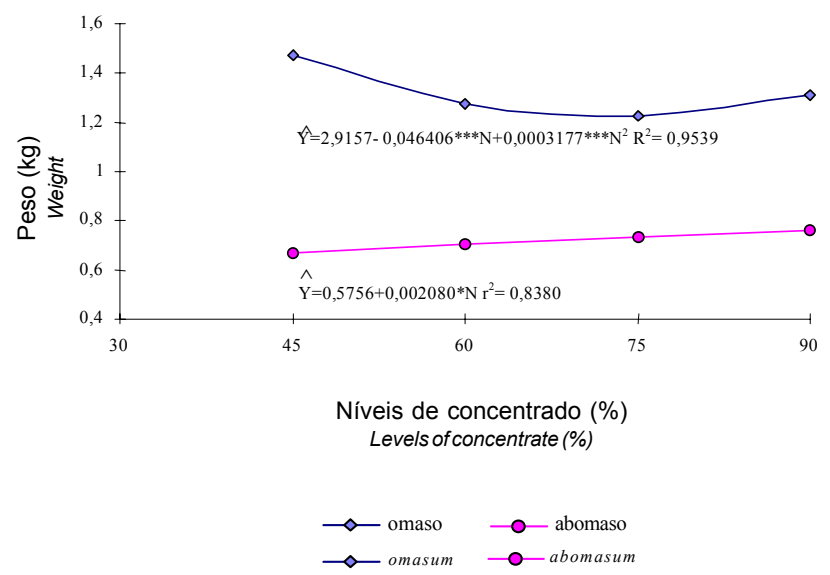

Figura 3 - Estimativa do peso absoluto do omaso e abomaso dos animais, em função dos níveis de concentrado nas dietas.

Figure 3 - Estimate of the absolute weight of the omasum and the abomasum, in relation to the levels of concentrate in the diets.

(Strozinski et al., 1971 e Warner et al., 1956, citados por LUCCI, 1989).

Na Figura 4 é apresentada a equação de regressão para o peso de mesentério nos animais alimentados com diferentes níveis de concentrado em suas dietas, assim como o peso da gordura interna.

Observou-se que os animais alimentados com dietas contendo $90 \%$ de concentrado apresentaram maior proporção de gordura interna que os alimentados com $45 \%$ de concentrado. Estes resultados estão de acordo com diversos tarabalhos relatados por JONES et al. (1985), que encontraram grandes quantidades de gordura visceral em animais alimentados com dietas altamente energéticas, quando comparadas a dietas medianamente energéticas. Constataram, também, que a deposição de gordura, nas partes não-integrantes das carcaças, aumenta em taxa semelhante à gordura presente na carcaça. Essa partição de gordura corporal com maior proporção de gordura interna, em animais de aptidão leiteira, traria como conseqüência prática, maior exigência para energia de mantença, de acordo com Thompson et al. (1983) e Solais et al. (1988), citados por PERON (1991), devido à maior atividade metabólica do tecido adiposo.

As análises de variância não mostraram efeito significativo $(\mathrm{P}>0,05)$ nas variáveis: couro, patas, cabeça, sangue e cauda, para os níveis de concentrado nas dietas.

A Figura 5 mostra a equação de regressão linear

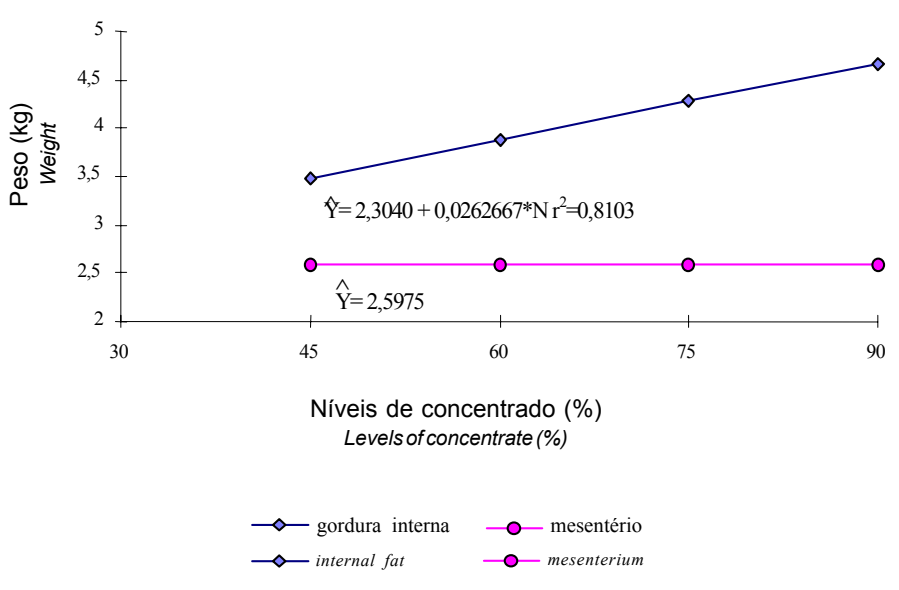

Figura 4 - Estimativa do peso do mesentério e da gordura interna $(\mathrm{kg})$, nos animais alimentados com dietas contendo diferentes níveis de concentrado.

Figure 4 - Estimate of weight of the mesenterium and of the internal fat $(\mathrm{kg})$, of the animals fed with diets containing various levels of concentrate.

$(\mathrm{P}<0,01)$ para sangue e demais variáveis, que se mantiveram constantes para todos os níveis de concentrado estudados no presente trabalho.

O rendimento de carcaça, segundo PERON (1991), é influenciado diretamente pelos pesos da cabeça, couro e trato gastrintestinal. A Figura 5 mostra que os valores encontrados para couro, patas

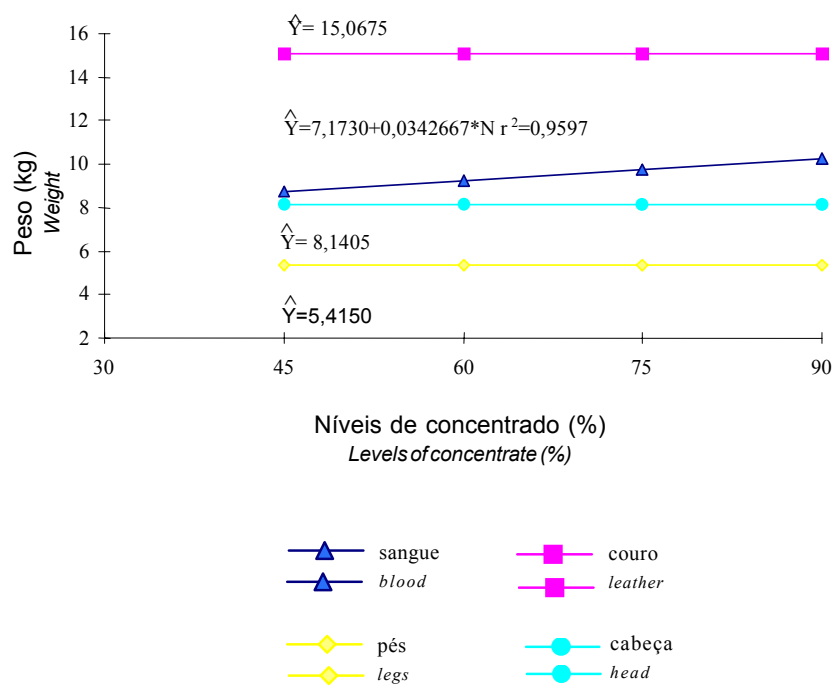

Figura 5 - Estimativa do peso absoluto de couro, patas, cabeça e sangue de animais alimentados com dietas contendo diferentes níveis de concentrado.

Figure 5 - Estimate of absolute weight of leather, legs, head and blood of animals fed with diets containing various levels of concentrate.

Rev. bras. zootec., 30(6S):2163-2168, 2001 
e cabeça foram constantes para todos os níveis de concentrado estudados. Como já foi comentado anteriormente, o tamanho relativo dos órgãos e das vísceras foi maior para aqueles animais alimentados com $90 \%$ de concentrado, o que pode explicar o fato desses animais terem apresentado maior quantidade de sangue no corpo, pois a mesma foi proporcional ao tamanho relativo dos órgãos.

\section{Conclusões}

Os níveis de concentrado na dieta tiveram influencia sobre o tamanho relativo do omaso, abomaso, coração, rins, fígado e pulmões, além da quantidade de gordura interna. Com relação às partes não constituintes da carcaça, apenas a mesma foi afetada.

\section{Referências Bibliográficas}

ALBOSPINO, B.H.J.C., LOBATO, J.F. 1994. Efeito do desmame precoce de bezerros no desempenho até os 24-26 meses de idade. R. Soc. Bras. Zootec., 23(4):565-575.

BERG, R.T., BUTTERFIELD, R.M. 1979. Nuevos conceptos sobre desarrollo de ganado vacuno. Zaragoza: Ed. Acribia, $297 \mathrm{p}$.

BOND, J., HOOVEN JR., N.W., WARICK, E. et al. 1972. Influence of breed and plane of nutrition on performance of dairy, dual-purpose and beef steers. II. From 180 days of age to slaughter. J. Anim. Sci., 34(6):1046-53.

DODE, M.A.T., JARDIM, P.O.C., OSÓRIO, J.C.S. et al. 1986. Estimativas dos principais cortes e da porção comestível da carcaça, em novilhos holandês PB. Pesq. Agropec. Bras., 21(1):771-779.

FERREL, C.L., GARRET, W.N., HINMAN, N. 1976. Estimation of body composition in pregnant and non pregnant heifers. J. Anim. Sci., 42(5):1158-1166.

FERREL, C.L., JENKINS, T.G. 1985. Cow type and nutritional environment: nutritional aspects. J. Anim. Sci., 61(3):725-741.

FERREL, C.L., KOONG, L.L., NIENABER, J.A. 1986. Effect of previous nutrition on body composition and maintenance energy costs of growing lambs. Br. J. Nutr., 56(3):595-605.

FREITAS, J.A. Composição corporal e exigências de energia e proteina de bovinos (zebuinos e mestiços) e bubalinos nãocastrados, em confinamento. Viçosa, MG: UFV, 1995. 75p. Dissertação (Mestrado em Zootecnia) - Universidade Federal de Viçosa, 1995.

GALVÃO, J.G.C., FONTES, C.A.A., PIRES, C.C. et al. 1991. Características e composição física da carcaça de bovinos não castrados, abatidos em três estágios de maturidade de três grupos raciais. R. Soc. Bras. Zootec., 20(5):502-512.
HANSKINS, O.G., HOWE, P.E. 1946. Estimation of the composition of beef carcasses and cuts local, USDA, Tech. Bulletin - USDA, 926.

JARDIM, P.O.C., ZIEGLER, J.C.S., OSÓRIO, J.C.S. 1983. Efeito da raça e idade sobre o peso da carcaça e o peso e percentagem dos principais cortes em novilhos. R. Soc. Bras. Zootec., 12(3):551-562.

JONES, S.D.M., ROMPALA, R.E., JEREMIAH, L.E. 1985. Growth and composition of the empty body in steers of different maturity types fed concentrate or forage diets. J. Anim. Sci., 60(2):427-433.

JORGE, A.M. 1993. Ganho de peso, conversão alimentar e características da carcaça de bovinos e bubalinos. Viçosa, MG: UFV, 1993. 97p. Dissertação (Mestrado em Zootecnia) Universidade Federal de Viçosa, 1993.

LUCCI, C.S. 1989. Bovinos leiteiros jovens. São Paulo: Nobel/ EDUSP. $371 \mathrm{p}$.

MÜLLER, L. 1980. Normas para avaliação de carcaças e concurso de carcaças de novilhos. Santa Maria, RS. 31p.

NATIONAL RESEARCH COUNCIL - NRC. 1988. Nutrient requirements of dairy cattle, Washington, D.C. National Academic Press. 90p.

OLIVEIRA, M.A.T., FONTES, C.A.A., LANA, R.P. et al. 1994. Biometria do trato gastrintestinal e área corporal de bovinos. R. Soc. Bras. Zootec., 23(4):576-584.

PERON, J.A. Características e composição física e química, corporal e da carcaça de bovinos de cinco grupos genéticos, submetidos à alimentação restrita e "ad libitum". Viçosa, MG: UFV, 1991. 126p. Dissertação (Mestrado em Zootecnia) Universidade Federal de Viçosa, 1991.

PRESTON, T.R., WILLIS, M.B. 1974. Intensive beef production. 2.ed. Oxford: Pergamon Press. 546p.

UNIVERSIDADE FEDERAL DE VIÇOSA - UFV. 1995. S.A.E.G. (Sistema de Análises Estatísticas e Genéticas). Viçosa, MG (Versão 5.0).

VELLOSO, L., SILVA, L.R.M., BOIN, C. et al. 1975. Desenvolvimento de bovinos mestiços Holandesesss inteiros e castrados, em regime de confinamento e as características das carcaças. Bol. Ind. Anim, 32(1):37-45.

Recebido em: 28/08/00

Aceito em: 19/05/01 